\title{
GLL
}

Geomatics, Landmanagement and Landscape No. $2 \cdot 2020,111-118$

\section{SELECTED EXAMPLES OF HISTORICAL CARTOGRAPHY}

\author{
Tadeusz Żaba, Izabela Piech
}

\begin{abstract}
Summary
In World War II, the Battle of Monte Cassino (also called the Battle of Rome) was a breakthrough moment of the Italian campaign.

The Battle of Monte Cassino, which was remarkably vicious and ruthless, lasted nearly five months. During the entire Italian campaign, which ran from 3 September 1943 to 2 May 1945, the Allies lost nearly 312,000 soldiers and Germans suffered about 435,000 killed and injured, i.e. an average of 1,233 people per day for both sides. The most fierce fights took place on the Gustav Line: Germans, Italians, Americans, French, British, Indians, New Zealanders, Poles, Canadians and South Africans lost about 200,000 soldiers within 129 days. The 2nd Polish Corps alone had 924 dead, 2930 injured and 345 missing.

During the recognition of the site and the preparation of the assaults, soldiers of the 12th Geographical Company of the 2nd Polish Corps drew, alongside maps, many perspective sketches of hills and structures from several observation posts. The authors attempted to analyse selected sketches, in terms of their geometric parameters and compatibility with a map made in 1944 , based on aerial photographs. Some of these sketches are not perspective drawings but panoramic (mapped on cylindrical or spherical surface), with specified angular graduation and distances. Probably, they were to be used for artillery fire - which is proven by their precision. The art of the terrain's details is also noteworthy. On the other hand, photogrammetric observations, unlike geodesic ones, are not made directly on the measured object, but indirectly on properly taken photographs. They are called measuring photos or photograms. The basic requirement for measuring photos is their fidelity with a central projection (which, in view of the imperfections of image extraction techniques, is only its closest mathematical model). After taking pictures, the actual dimensions and shape of the area or object recorded in the pictures are determined by awareness of the conditions under which these photos were taken (shooting distance and camera type). For these reasons, photogrammetric methods have been used in archaeology, architecture and preservation of monuments, astronomy, ballistics, construction, geology, mining, hydrology, forensics, forestry, medicine, automotive and shipbuilding industries, and especially in surveying and cartography.
\end{abstract}

\section{Keywords}

panoramic parameters $\bullet$ geometrical parameters • aerial photographs $\bullet$ Monte Cassino 


\section{Introduction}

The Battle of Monte Cassino (also known as the Battle of Rome), a series of battles rather than a single military confrontation, proved to be a critical moment in the Italian campaign. It was held from 17 January to 19 May 1944 near the Monte Cassino Abbey. As the Germans were aware that the Monte Cassino hill is a strategic site, they built the so-called "Gustav Line" - a line of fortifications on a number of surrounding hills, which due to their arrangement and height formed a natural obstacle on a considerable width of the Apennine Peninsula. This line closed off for allied armies the possibility of direct invasion from southern Italy towards Rome. Beside American, British, Indian and New Zealand units, the Allied forces consisted in soldiers of the 2nd Polish Corps under the command of General Anders. During the recognition of the site and the preparation of the assaults, soldiers of the 12th Geographical Company of the 2nd Polish Corps not only drew maps, but also many prospective sketches of hills and structures from several observation and artillery posts.

\section{Geometric basics of photographic images}

There are different types of photogrammetric projections: central, central-orthogonal, panoramic and orthogonal. The easiest to obtain, reproduce and develop is central projection, which is why it has been used in most photogrammetric studies. Central projection is made by photographic cameras.

It is a geometric mapping that assigns to each point of a given geometrical figure $G$ a specific point in space in such a way that the discussed figure $G$ is transformed into a new figure G. Figure G' is called an image of figure G (Fig. 1). If a given figure F lies in any plane, and through any point $\mathrm{O}$, not lying within this plane, we lead straight lines a, b, c..., which pass through successive points A, B, C... belonging to figure $G$, then after crossing these lines with a plane $\pi$, called a projection plane, they will give respectively points A', B', C'... of figure G. Figure G' is the central projection of figure $G$, on a plane $\pi$.

A photo is a central projection when:

- camera lens is free of distortion,

- film or CCD forms a perfect plane at the time of shooting,

- image in a photo is not deformed during photochemical treatment or storage process,

- camera shutter does not distort the image,

- atmospheric refraction does not distort the image, or when

- distortions caused by these factors are eliminated.

A photo can be called a measuring photo if the distortions resulting from the above factors are within acceptable limits. Aerial photos are taken with aerial, analogue or digital cameras. Until recently, analogue aerial cameras were the only instruments for photographing the surface. The operation of these devices consisted of passing light 
through the lens and photographing the image of a terrain on photosensitive material, i.e. all kinds of plastics and other materials that are sensitive to light.

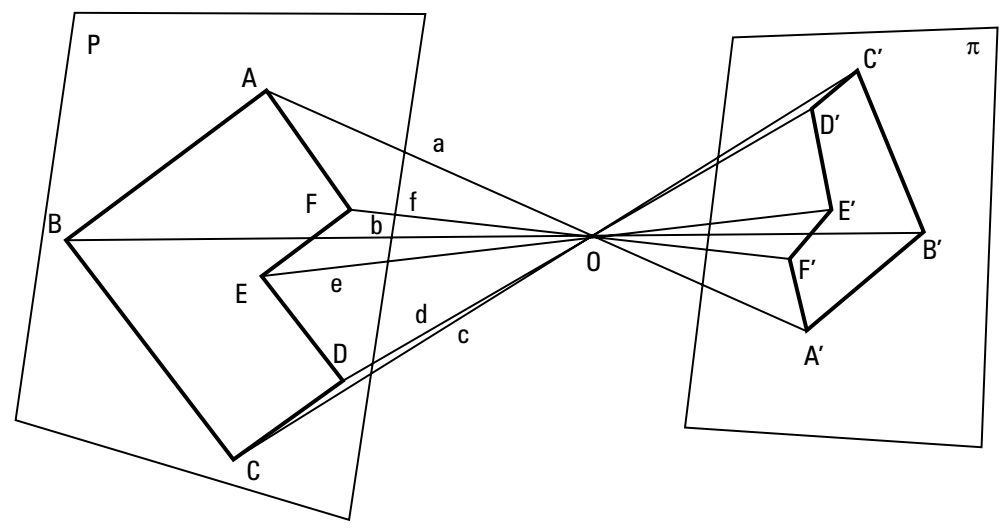

Source: Buttowt and Kaczyński [2010]

Fig. 1. Central projection - mapping diagram

This methodology was used during aerial reconnaissance of the fighting area and fortifications built by the German Army, and based on the aerial photographs taken by RAF planes at that time. The most current maps of the Monte Cassino area were made in 1944.

Regardless of that, scouts took ground photos of the objects that were later captured, but only from locations they could access. On the other hand, sketches often appeared as if from a place where an observer could be found sketching, if it were not under fire. This form of drawing, based on the idea of what the presented object would look like from a different point than the author of the sketch, required a spatial imagination, allowing a proper transformation of the resulting drawing in relation to the actual observation, corresponding to the geometric transformation determined by central collineation.

\section{Results}

The analysis of the sketches of the area near Monte Cassino showed the mapping method, the use of geodetic measurements during their development and confirmed their accuracy for realising military objective.

A significant part of the drawings are sketches of selected fragments of fortifications, made from distance, but presenting what a soldier will see from the point of view he will find himself in during an attack. These sketches were made by drafters from the 12th Geographical Company of the 2nd Polish Corps according to central projection on image plane (Fig. 2). They were supposed to familiarise the attackers with the surroundings - indicating specific and strategically important sites, e.g. a hole in the wall, through 
which one could get into the abbey. After capturing the land, ground photographs of the sketched objects were taken, often from places corresponding to the apparent viewpoints of drafters from the 12th Geographical Company of the 2nd Polish Corps. These photographs confirmed the detailed and precise presentation of the objects on sketches, differing usually in result of additional damage caused by bombing and artillery fire. This accuracy is demonstrated by a set of perspective drawings made as if from the road leading to the Monte Cassino monastery, and photographs taken later from a similar position after capturing the area, inaccessible at the moment of drawing.

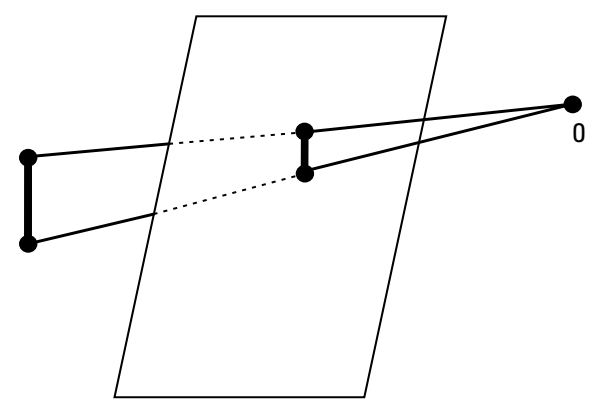

Source: Authors' own study

Fig. 2. Perspective drawing - mapping diagram by central projection onto image plane of some perspective sketches of the fighting region of Monte Cassino made by soldiers of the 12th Geographical Company of the 2nd Polish Corps

Not every sketch is a perspective mapping against a plane. Some have angular graduation lines, both horizontally and vertically, forming an angular grid as a background for the sketches (Fig. 3).

An identical linear length between the meridians distant by the same angular value (horizontal angles) and different linear lengths between vertical parallel lines distant by the same angular value (vertical angles) on this grid indicate a projection on a surface of a cylinder, with the centre of projection on the axis of that cylinder - these are therefore panoramic sketches (Fig. 4). Panoramic projection is more difficult to depict in a flat picture compared to a traditional central projection on a plane. For this reason, painters mapping on a cylindrical surface, such as the Panorama Racławicka exhibited at the Art Museum in Wrocław or the installation at the Panorama Museum of the Battle of Borodino in Moscow, were aware that their works will be presented in the form of waltzes in rotundas for viewers standing in their centre. They helped themselves by spreading the canvas inside a cylindrical surface. In addition, Russian painter-batter Franz Aleksiejewicz Roubaud, who made the latter painting of impressive dimensions (the height is 14 meters, circumference 115 meters, diameter 36 meters), anticipated the movement of spectators around the circle and adapted the observation point to this movement. Also, to enhance the feeling of reality, real exhibits from the battlefield were placed around the perimeter. 


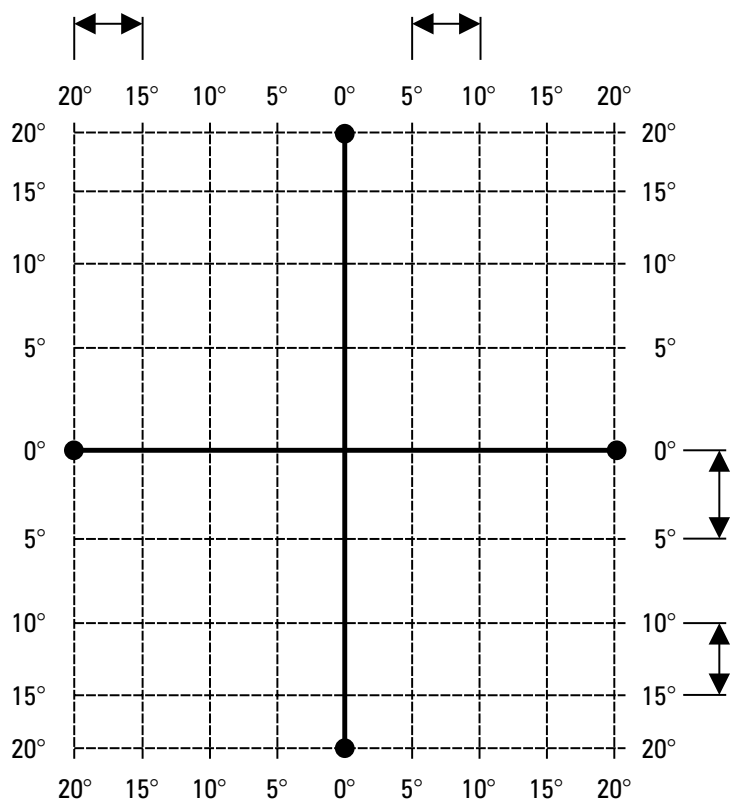

Source: Authors' own study

Fig. 3. An angle grid constituting the background of some perspective sketches of the Monte Cassino battle region, made as a panoramic drawing (mapping on a surface of a cylinder) by soldiers of the 12th Geographical Company of the 2nd Polish Corps

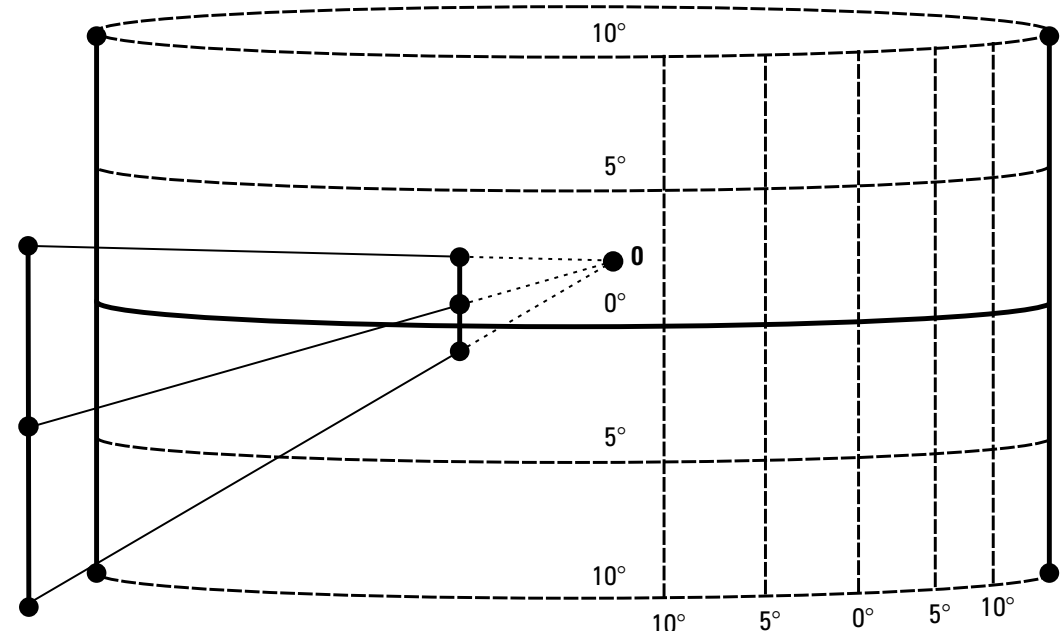

Source: Authors' own study

Fig. 4. Panoramic drawing - mapping diagram on a surface of a cylinder (a centre of projection on the axis of this cylinder) of some perspective sketches of the combat area near Monte Cassino made by soldiers of 12th Geographical Company of the 2nd Polish Corps 


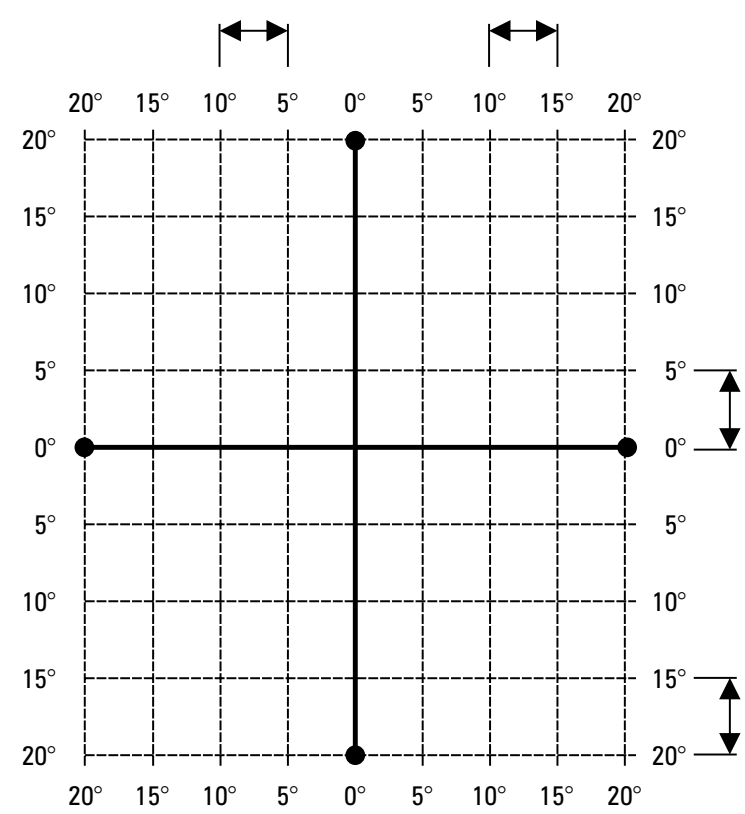

Source: Authors' own study

Fig. 5. An angle grid constituting the background of some perspective sketches of the Monte Cassino battle region, projected onto a spherical surface (mapping on a surface of a cylinder) by soldiers of the 12th Geographical Company of the 2nd Polish Corps

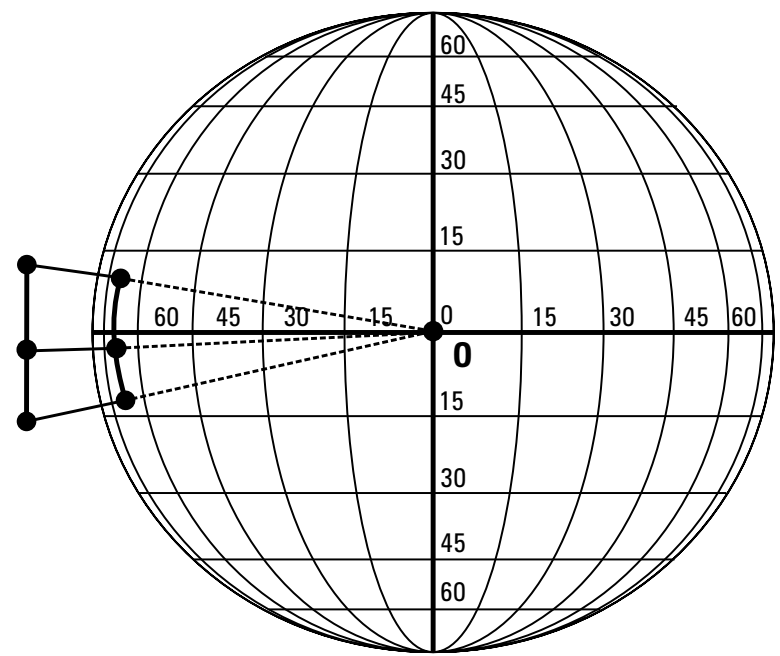

Source: Authors' own study

Fig. 6. Mapping diagram on a spherical surface (mapping on a surface of a cylinder) of some perspective sketches of the Monte Cassino battle region by soldiers of the 12th Geographical Company of the 2nd Polish Corps 
Detailed analysis of some sketches showed on the angular grid (Fig. 5), constituting their background, an equal linear length between parallel lines, distant by the same horizontal and vertical angular value, which confirms the projection on a spherical, not cylindrical surface (Fig. 6). The centre of this projection is also the centre of a sphere.

Geodesic instruments were probably used to perform these sketches, described as individual artillery stations, with polar coordinates (horizontal and vertical angular graduation and distances), and to prepare precise data for planning fire. The method of this mapping is used to present the distribution of objects on the sky map in places such as the Władysław Dziewulski Planetarium in Toruń.

\section{Conclusions}

1. Analysis of sketches of the Monte Cassino area made by soldiers of the 12th Geographical Company of the 2nd Polish Corps confirms their accuracy and even artistic reproductions of the details of the site.

2. Not every sketch is a perspective drawing against a plane. Some of them are representations on the surface of a cylinder, or panoramic drawings with polar coordinates.

3. Detailed analysis of some sketches showed on the angular grid (Fig. 5), constituting their background, an equal linear length between parallel lines, distant by the same horizontal and vertical angular value, which confirms the projection on a spherical, not cylindrical surface (Fig. 6). The centre of this projection is also the centre of a sphere.

4. In order to include panoramic polar coordinates in sketches required the soldiers of the 12th Geographical Company of the 2nd Polish Corps to employ geodesic instruments.

5. The way the sketches are dimensioned with polar coordinates (angular values and distances) indicates their purpose. They were probably drawn from prepared artillery positions.

\section{References}

Butowtt J., Kaczyński R. 2010. Fotogrametria. Wojskowa Akademia Techniczna, Warszawa. Moskwa. Miasto jak na dłoni. 2006. National Geographic.

Otto F., Otto E. 1980. Podręcznik geometrii wykreślnej. PWN, Warszawa.

Szkice perspektywiczne terenów walk pod Monte Cassino maj 1944. 1984. Krajowa Agencja Wydawnicza, Kraków.

https://pl.wikipedia.org/wiki/Wikipedia. 
Dr inż. Tadeusz Żaba

Politechnika Krakowska

Katedra Wodociągów, Kanalizacji i Monitoringu Środowiska

ul. Warszawska 24, 31-155 Kraków

e-mail: tadeusz.zaba@interia.pl

ORCID: 0000-0002-0967-164X

Dr inż. Izabela Piech

Uniwersytet Rolniczy w Krakowie

Katedra Geodezji Rolnej, Katastru i Fotogrametrii

ul. Balicka 253a, 30-198 Kraków

e-mail:rmpiech@cyf-kr.edu.pl

ORCID: 0000-0002-6710-4387 